\title{
Performance Evaluation of Some Private Sector Bank Sponsored Midcap Funds
}

\author{
${ }^{1}$ B. Raja Mannar, ${ }^{2}$ Dr.B. Ramachandra Reddy \\ Department of Commerce, Sri Venkateswara University, Tirupati, 517 502, India
}

\begin{abstract}
The performance of few selected Midcap funds, HDFC, ICICI Prudential, Kotak Mahindra and Axis funds have been studied from their inception to the present financial year. The returns are compared with the market returns. The evaluation parameters Sharpe Index. Treynor Index, Jensen's Alpha, Fama's Measure and $\mathrm{M}^{2}$ have been computed for evaluation. Pearson correlation of these parameters is also reported.
\end{abstract}

Key Words: Midcap Funds, Evaluation Parameters, Mutual Funds

\section{Introduction:}

The development and liquidity of stock markets strongly depends on the development of a class of allgoverned institutional investors. There are three types of institutional investors, the first being the pension funds and the second the insurance. Investment and mutual funds form the largest group in transition economies. Investment and mutual funds form the largest group in transition economies. Investment funds largely emerged out of the mass privatisation funds used to transfer ownership during privatization. Over the last few years, the mutual fund industry in transition economies has exploded. Recent Studies (1) fund substantial cross country variation in the development of the fund industry.

Evaluation of the performance of a fund is far from being academic. Earlier, the investors were almost exclusively interested in funds having large annual return, the funds capable of eating the market. Meanwhile, many funds with outstanding profits during their life have collapsed, and the investors are more and more interested in the factor, risk.

The present paper is devoted to evaluate the performance of a few midcap funds and try to assess and rank them on the basis of different parameters.

Time and time again, there is one investment that catches investors' fancy. And this investment is touted as a surefire way to make fast bucks. This time around, it is the mid-cap stocks that have taken centre stage. Investors have been looking at the wonderful promise of midcap gains and have gone into a frenzy of pumping money into these stocks and the funds that specialize in them. The past year has seen the Nifty (stock index of the National Stock Exchange) post impressive gains of $42.60 \%$.

The funds that have been chosen for the study are primarily sponsored by private sector banks which are eye-catching for the researcher. The essence is to spot them young and watch them grow.

\section{Sample Compilation:}

The midcap funds selected for the evaluation include

2.1 HDFC Midcap Fund: The fund aims to generate long term capital appreciation that is substantially constituted of equity and equity related securities of small and mid cap companies.

2.2 ICICI Midcap Fund: The scheme aims to generate capital appreciation by actively investing in diversified mid cap stocks. It will invest primarily in companies that have a market capitalization between Rs. 100 crores to Rs. 2000 crores

2.3 Kotak Mahindra Midcap Fund: An open-ended scheme that invests in mid-cap companies that have a potential to become tomorrow's large-caps. The key focus of the fund is to identify potential stocks that are likely to grow in the long term. The essence is to 'spot them young and watch them grow'. It endeavors to take advantage of the successive waves of opportunity provided by a transitioning economy. The portfolio is diversified across sectors, with adequate flexibility to move within sectors.

2.4 Axis Midcap Fund: Like any other equity fund, it invests in a basket of stocks. But unlike large cap equity funds, it invests in carefully chosen mid sized companies that have the potential to offer more returns than the usual large blue chip companies. While this means that it carries greater risk and volatility, it's just what you might need to provide for that extra that an investor wants.

The period of study being from the date of inception to the end of financial year 2011-12 as the funds of recent origin. NAV values were collected from the respective web sites of the funds, for the period of study for all the schemes and the monthly returns were computed and compounded to obtain the annualized returns. $\left(\mathrm{R}_{\mathrm{P}}\right)$. 
Similarly, the NAV values of the market index, CNX Midcap was collected and processed to obtain the market returns. $\left(\mathrm{R}_{\mathrm{M}}\right)$ The standard deviation, $\sigma_{\mathrm{P}}$ and $\sigma_{\mathrm{M}}$ are evaluated.

Risk free rate of return is the obtainable rate of return from investing in a risk free asset. The asset with the known terminal value is risk free asset. Government securities and deposits in national Banks fall under this category. Interest rate earned on the savings bank deposit of State bank of India is selected as the risk free rate in the present study.

The rate of return offered by SBI on savings bank deposit is 4\% for the financial year 2011-12 and 2002-03 and for the financial years 2003-04 through 2009-2010 it is 3.5\% per annum. Average risk free monthly returns are $0.330 \%$ and $0.292 \%$ respectively.

\section{The Statistical Tools:}

The data obtained has been analysed with the statistical tools, Correlation between $R_{P}$ and $R_{M}$.

Funds usually try to attract potential investors by referring to their past performance. The past performance may always does not guarantee or even directly relate to future performance, It usually serves as an initial step in the process of investment decision. Several investigations are reported for the predictability of funds. (2, 3,4, 5,6,7,8 \& 9). The following risk/return measures should rather be referred to as ex-post measures because they are defined as historical averages, rather than expectations of future performance. Statistical measures are used to assess risk. For evaluations of risk of mutual funds the most commonly used are, correlation with market return, standard deviation of returns, and Sharpe, Treynor and Jensen and Fama's measures.

Standard deviation measures fluctuations of returns around their mean value. Standard deviation of a fund represents the total risk, which can be separated into systematic (market risk) and unsystematic risk through the

relation $\sigma^{2}=\beta^{2} \sigma_{M}^{2}+\sigma_{e}^{2} \quad \beta^{2} \sigma_{M}^{2}$, is directly related to the beta coefficient. Unsystematic risk, $\sigma_{e}^{2}$, can be reduced or even eliminated through the proper diversification of the fund.

Sharpe (loc,cit.) introduced a measure for the performance of mutual funds and proposed the term "reward-tovariability ratio" to describe it. While the measure has gained considerable popularity, the name has not. Other authors have termed the original version the Sharpe Index $(10,11)$, the Sharpe Measure $(12,13,14)$, or the Sharpe Ratio (15). Generalized versions have also appeared under various names $(16,17)$. The calculation of the original Sharpe ratio is straightforward, defining the "excess return" as the return of risky investment in excess of the return on a risk-free investment. The annualized Sharpe ratio is calculated by dividing the annualized excess return by the standard deviation of the return:

$$
S_{h}=\frac{R_{P}-R_{F}}{\sigma}
$$

The Sharpe ratio, as a measure of risk, uses the total risk or standard deviation of returns. The advantage of using the Sharpe ratio for evaluating portfolios is that it does not depend on the choice of a benchmark (RM).

The Treynor ratio $(\mathrm{Th})$ is another popular indicator of fund performance, given by

$$
T_{h}=\frac{R_{P}-R_{F}}{\beta}
$$

The Sharpe and Treynor measures are similar in a way, since they both divide a fund's excess return by a numerical risk measure. The total risk is appropriate when we are evaluating the risk return relationship for poorly diversified portfolios. On the other hand, the systematic risk is the relevant measure of risk when we are evaluating fully diversified portfolios. For a well diversified portfolio, the total risk is equal to systematic risk. Rankings based on total risk (Sharpe measure) and systematic risk (Treynor measure) should be identical for a well-diversified portfolio, as the total risk is reduced to systematic risk. Therefore, a poorly diversified fund that ranks higher on the Treynor measure, compared with another fund that is highly diversified, will rank lower on the Sharpe Measure.

The other parameter of the CAPM model, Jensen's $\alpha$, indicates whether the portfolio manager is superior or inferior in stock selection compared to the market, the difference between a portfolio's actual and expected return given its level of systematic risk. Annualized Jensen's $\alpha$ is the maximum amount of money the investor should be willing to pay a fund manager per year. An inferior manager has a Jensen's $\alpha$ that is significantly negative, while a superior manager obtains a positive value of $\alpha$.

According to Jensen (18), equilibrium average return on a portfolio would be a benchmark. Equilibrium average return is the return of the portfolio by the market with respect to systematic risk (volatility) of the portfolio. This is a return the portfolio should earn with the given systematic risk. The difference between the equilibrium average return and the average return of the portfolio indicates superior performance of the fund. This is called alpha $(\alpha)$. The appraisal ratio adjusts Jensen's $\alpha$ for unsystematic risk through 


$$
A R_{h}=\frac{\alpha}{\sigma_{e}}
$$

The smaller the unsystematic risk, the better the results the fund has established as measured by the appraisal ratio.

The Treynor-Mazuy model (19) shows a manager's ability to shift a fund's beta between riskier and less risky assets according to overall stock market movements. It is defined by including the squared market risk premium in the CAPM model of eq. 2. If the coefficient of that new term is positive, then the manager shows timing ability:

$$
R_{t}=R_{f}+\alpha+\beta_{1}\left(R_{M}-R_{f}\right)+\beta_{2}\left(R_{M}-R_{f}\right)^{2}+\varepsilon_{t}
$$

Jensen's Measure is the excess return over the expected return based on premium for systematic risk. Eugene F Fama goes a step ahead and suggests a measure to find outperformance in terms of excess returns over expected return based on premium for total risk. Fama suggests a framework of performance breakdown that distinguishes the part of the observed return that is due to the ability to pick the best securities of a given level of risk from the part that is due the predictions of general market price movements. Here too, CAPM is used as a benchmark. The framework splits the overall performance, which is the difference between the return on the chosen portfolio and the risk free return, into selectivity and risk. The measure of selectivity is further split into net selectivity and compromise in diversification. It was opined that the portfolio performance can be judged by net superior returns due to selectivity. Fama's Measure $\left(\mathrm{F}_{\mathrm{P}}\right)$ is given by

$$
F_{P}=\left(R_{P}-R_{f}\right)-\left(\frac{\sigma_{P}}{\sigma_{M}}\right)\left(R_{M}-R_{f}\right)
$$

A positive value of $F_{\mathrm{P}}$ indicates that the fund has returned higher than expected returns and lies above CML and negative value indicates that the fund earned returns less than the expected returns and lies below CML.

The relative measures of performance, the Sharpe or Treynor Index are simple and primarily used to rank the funds. The numerical values of these parameters are not easy to interpret. Modigliani proposed a variant of Sharpe Index named $\mathrm{M}^{2}$ Measure. Unlike Sharpe Index, $\mathrm{M}^{2}$ is an absolute measure of return. Like Sharpe Index, this measure uses total volatility as a measure of risk and reflects the proposition that by choosing a portfolio for investing matters in measuring its performance, is total risk, and not just systematic risk. However, its risk adjusted measure of performance has the easy interpretation of a differential return relative to the benchmark index. Performance can be simply be measured by comparing the returns from the market index and that of adjusted portfolio. This performance measure is defined as

$$
M^{2}=\left[\frac{\sigma_{M}}{\sigma_{P}}\left(R_{P}\right)+1-\left(\frac{\sigma_{M}}{\sigma_{P}}\left(R_{P}\right)\right)\right]-R_{M}
$$

The $\mathrm{M}^{2}$ is the difference between the two returns. When the capital Allocation Line (CAL) of the portfolio is less steep than CML, $\mathrm{M}^{2}$ would be negative, signifying below normal performance of the fund manager. When the CAL is steeper than CML, $\mathrm{M}^{2}$ will be positive, signifying above normal performance of the fund manager.

\section{Limitations:}

1. The basic limitation for the study is the funds are of recent origin and are emerging.

2. Investments decisions taken based on statistical data might not yield desired returns.

3. All the caveats attached to funds will apply to the funds selected for this study.

4. Banks are free to accept deposits at any interest rates within the ceiling fixed by Reserve Bank of India. Hence there can be possibility in the accuracy of risk free rates.

\section{Results \& Conclusion:}

The $R_{P}$ of the selected funds, corresponding $R_{M}$ values and their $\sigma$ values are included in Table. 1 for comparison. The performance of the funds was less than the market in most of the cases as can be understood from the fact that these are the funds of recent origin. The pearson correlation coefficient was also attempted to study the correlation between $\mathrm{R}_{\mathrm{P}}$ and $\mathrm{R}_{\mathrm{M}}$. However no conclusions could be drawn as expected based on statistical considerations.

The results of the statistical evaluation parameters are presented in Table.2. Sharpe Rule stipulates that in assessing the comparative merits of the funds a fund with higher $S_{h}$ is to be chosen. An investor with a different risk performance might prefer a different base. In the present instance the $S_{h}$ values are all negative. 
Treynor indices of all the funds are negative with the exception of Kotak Mahindra Midcap Fund. In terms of $\alpha_{\mathrm{J}}$, only the performance of ICICI Prudential Midcap Fund was satisfactory. $F_{\mathrm{P}}$ values enumerate the better and average performance of HDFC and ICICI Prudential Funds and similar was the observation with respected to $\mathrm{M}^{2}$. Inter correlation results of these parameters, Pearson Correlation, is included in Table.3.

Though no foolproof definite conclusion could be drawn from the present data, the work is clearly indicative and suggests the continuous monitoring of these infant funds.

\section{Acknowledgements:}

The authors are thankful to the authorities of Sri Venkateswa University, Tirupati for providing the necessary facilities and Head, Department of commerce for useful discussions and encouragement.

TABLE.1. $R_{\mathrm{P}}, \mathbf{R}_{\mathrm{M}}, \sigma_{\mathrm{P}}, \sigma_{\mathrm{M}}$ and Pearson Correlation Coefficients

\begin{tabular}{|c|c|c|c|c|c|c|c|}
\hline Year & 2011-12 & $2010-11$ & $2009-10$ & $2008-09$ & $2007-08$ & $2006-07$ & $2005-06$ \\
\hline \multicolumn{8}{|c|}{ i. HDFC Midcap Fund } \\
\hline $\mathbf{R}_{\mathbf{P}}$ & 0.0024 & 0.0078 & 0.0629 & -0.0525 & 0.0323 & & \\
\hline$\sigma_{\mathbf{P}}$ & 0.0583 & 0.05831 & 0.05831 & 0.05831 & 0.0583 & & \\
\hline $\mathbf{R}_{M}$ & 0.0064 & 0.0072 & 0.0619 & -0.0373 & -0.4798 & & \\
\hline$\sigma_{M}$ & 0.0003 & 0.0003 & 0.0003 & 0.0003 & 0.0003 & & \\
\hline \multicolumn{8}{|c|}{ Correlation coefficient :0.1293 } \\
\hline \multicolumn{8}{|c|}{ ii. ICICI Midcap Fund } \\
\hline $\mathbf{R}_{\mathbf{P}}$ & -0.0078 & 0.0505 & -0.0680 & 0.0098 & -0.0014 & -0.1236 & -0.0118 \\
\hline$\sigma_{\mathrm{P}}$ & 0.0773 & 0.0523 & 0.0881 & 0.9320 & 0.0931 & 0.0823 & 0.2792 \\
\hline $\mathbf{R}_{M}$ & 0.0064 & 0.0072 & 0.0619 &.-0.0373 & -0.4798 & -0.0366 & 0.0361 \\
\hline$\sigma_{M}$ & 0.0666 & 0.0078 & 0.0253 & 0.10989 & 0.1071 & 0.1521 & 0.0578 \\
\hline \multicolumn{8}{|c|}{ Correlation coefficient $: \mathbf{0 . 0 6 5 0}$} \\
\hline \multicolumn{8}{|c|}{ iii. Axis Midcap Fund } \\
\hline $\mathbf{R}_{\mathbf{P}}$ & -0.0004 & 0.0141 & & & & & \\
\hline$\sigma_{\mathbf{P}}$ & 0.0525 & 0.0502 & & & & & \\
\hline $\mathbf{R}_{M}$ & 0.0064 & 0.0072 & & & & & \\
\hline$\sigma_{\mathrm{M}}$ & 0.06663 & 0.06025 & & & & & \\
\hline \multicolumn{8}{|c|}{ Correlation coefficient : 1.0000} \\
\hline \multicolumn{8}{|c|}{ iv.Kotak Midcap Fund } \\
\hline $\mathbf{R}_{\mathbf{P}}$ & 0.0056 & & & & & & \\
\hline$\sigma_{\mathbf{P}}$ & 0.00200 & & & & & & \\
\hline $\mathbf{R}_{M}$ & -0.0120 & & & & & & \\
\hline$\sigma_{\mathrm{M}}$ & 0.06025 & & & & & & \\
\hline
\end{tabular}

TABLE.2. Evaluation Parameters

\begin{tabular}{|l|c|c|c|c|c|}
\hline Fund: & $\mathbf{S}_{\mathbf{h}}$ & $\mathbf{T}_{\mathbf{h}}$ & $\boldsymbol{\alpha}_{\mathbf{J}}$ & $\mathbf{F}_{\mathbf{P}}$ & $\mathbf{M}^{\mathbf{2}}$ \\
\hline HDFC Midcap & -4.09 & -1.0162 & -0.2926 & 2.7743 & 0.3222 \\
\hline ICICI Prudential Midcap & -3.82 & -0.1607 & 1.4214 & 0.4621 & 0.4656 \\
\hline Axis Midcap & -2.56 & -0.09481 & -0.2365 & -0.2308 & -0.9262 \\
\hline Kotak Mahindra Midcap & -1.62 & 2.13075 & -0.3215 & -0.2221 & -8.7728 \\
\hline
\end{tabular}


TABLE.3 Rank correlation Coefficient

\begin{tabular}{|l|l|l|l|l|l|}
\hline & $S_{h}$ & $T_{h}$ & $\alpha_{J}$ & $F_{P}$ & $M^{2}$ \\
\hline$S_{h}$ & 1 & & & & \\
\hline$T_{h}$ & $0.924^{*}$ & 1 & & & \\
\hline$\alpha_{J}$ & 0.331 & -0.218 & 1 & & \\
\hline$F_{P}$ & 0.324 & -0.684 & -1.19 & 1 & \\
\hline$M^{2}$ & $0.970^{*}$ & -0.963 & 0.433 & 0.502 & 1 \\
\hline
\end{tabular}

Correlation is significant at the 0.05 level (1-tailed)

\section{Journal Papers:}

\section{References}

[1] 1.-Khorana, A., Servaes, H., and Tufano, P., 2005, "Explaining the size of mutual fund industry around the world", Journal of Financial Economics, 78,1.

[2] 2.-Sharpe, W.F., 1994,"The Sharpe Ratio". Journal of Portfolio Management

[3] 3. -Sharpe, W.F., 1966, "Mutual Fund Performance", Journal of Business, January, 119-138.

[4] 4.-Hendricks, D., Patel, J., and Zeckhauser, R., 1993, "Hot Hands in Mutual Funds: Short- Run Persistence of Relative Performance, 1974-1988", Journal of Finance, 48(1), 93-130.

[5] 5.-Malkiel, B., 1995, "Returns from Investing in Equity Mutual Funds 1971 to 1991", Journal of Finance, 50(2), 549-572

[6] 6.-Carhart, M., 1997, "On Persistence in Mutual Fund Performance”, Journal of Finance, Vol.52(1), 57-82.

Books:

[7] 1.-Bollen, P., and Busse, J.A., 2005, Short-term persistence in mutual fund performance Review of Financial Studies, 18, 569597.

[8] 2.-Otten, R., and Bams, D., 2002, European Mutual Fund Performance European Financial Management, 8, 75-101

[9] 3.-Blake, D., and Timmerman, A., 1998, Mutual fund performance: evidence from the UK European Finance Review, 57.

[10] 4.-Radcliff, R.C., 1990, Investment Concepts, Analysis, Strategy 3d edition, (New York: HarperCol- lins).

[11] 5.-Haugen, R.A., 1993, Modern Investment Theory, 3d edition, Englewood Cliffs, (NJ:

[12] Prentice-Hall).

[13] 6.-Bogle, J.C., 2000, Common Sense on Mutual Funds: New Imperatives for the Intelligent Investor (New York: John Wiley \& Sons).

[14] 7.-Elton J.E., and Gruber, M.J., 1991, Modern Portfolio Theory and Investment Analysis 4th edition, (New York: John Wiley \& Sons).

[15] 8.-Reilly, F.K., 1989, Investment Analysis and Portfolio Management 3d edition. (Chicago: The Dryden Press).

[16] 9.-Morningstar, 1993, Morningstar Mutual Funds User's Guide, Chicago: Morningstar Inc.

[17] 10.-BARRA, 1993, "BARRA Newsletter”, (September/October 1992, May/June 1993, Berkeley, Ca), p. 21.

[18] 11.-Treynor, J., and Mazuy, K, 1966, Can Mutual Funds Outguess the Market?, Harvard Business Review, 43, July-August, 131136. 